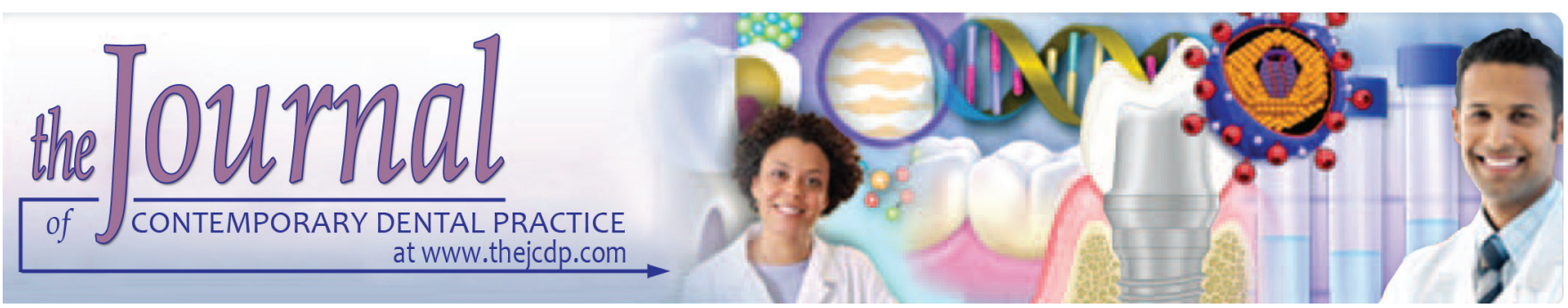

\title{
Sterilization and Biologic Monitoring in Private Dental Clinics in Lebanon
}

\author{
1Jihad Dagher, ${ }^{2}$ Charles Sfeir, ${ }^{3}$ Ahmad Abdallah, ${ }^{4}$ Zeina Majzoub
}

\begin{abstract}
Aim: The aim of the present study was to evaluate sterilization practices and effectiveness in the Lebanese private dental sector and identify potential factors contributing to sterilization failure.

Materials and methods: A 13-item questionnaire consisting of four demographic/professional questions and nine questions related to sterilization practices along with self-contained biologic indicators (SCBIs) were delivered to a representative sample of Lebanese private offices. Univariate statistics and bivariate analyses were performed to compare sterilization failure rates according to demographic, professional, and sterilization-related conditions.
\end{abstract}

Results: Out of the 560 dentists contacted, 205 dentists returned the completed questionnaires and undamaged processed SCBIs. The tested autoclaves $(n=134)$ were mostly dynamic air removal $(69.4 \%)$ and had a mean age of $10.5 \pm$ 6.9 years. The dry heat ovens $(n=71)$ were all static air and had $12.9 \pm 8.1$ years. The dental assistants performed the routine sterilization procedures in nearly $62 \%$ of the practices and sterilization cycles were run 4 to 6 times per week in $75 \%$ of the offices. Correct temperature/time ratios were applied in $97 \%$ of the autoclaves and $80.3 \%$ of the ovens. Few dental practices reported having preventive maintenance $(17.9 \%$ for the autoclaves and $14.1 \%$ for the ovens). Routine monitoring of sterilizer efficacy was infrequently performed and was mostly conducted using physical indicators. Sterilization failure rate was higher for the ovens $(16.9 \%)$ than for the autoclaves $(7.5 \%)$.

1Department of Pediatric and Public Dental Health, Faculty of Dental Medicine, Lebanese University, Beirut, Lebanon

${ }^{2}$ Department of Periodontics and Research, School of Dental Medicine, University of Pittsburgh, Pittsburgh, Pennsylvania USA

${ }^{3}$ Department of Health Data Management Administrator, Hammoud Hospital University Medical Center, Sidon, Lebanon

${ }^{4}$ Department of Periodontics, Faculty of Dental Medicine Lebanese University, Beirut, Lebanon

Corresponding Author: Jihad Dagher, Department of Pediatric and Public Dental Health, Faculty of Dental Medicine, Lebanese University, Beirut, Lebanon, e-mail: jihaddagher@hotmail.com
Incorrect temperature/time ratio was the main significant factor associated with sterilization failures.

Conclusion: The present study demonstrated a relatively high rate of sterilization failures in the Lebanese private dental sector and identified the human error in setting sterilization cycle parameters as the predominant cause of failure. These findings should prompt actions toward increasing knowledge of the sterilization processes and their monitoring among dental professionals and improving the quality control of sterilization through collaborative efforts among health authorities, dental schools, and associations.

Clinical significance: This study presents the first published data relative to sterilization practices and effectiveness in private Lebanese dental offices and provides a rationale to implement biologic monitoring protocols in Lebanon as long practiced in developed countries.

Keywords: Biologic indicator, Dentists, Lebanon, Private dental clinic, Sterilization.

How to cite this article: Dagher J, Sfeir C, Abdallah A, Majzoub Z. Sterilization and Biologic Monitoring in Private Dental Clinics in Lebanon. J Contemp Dent Pract 2018;19(7):853-861.

Source of support: Nil

Conflict of interest: None

\section{INTRODUCTION}

Sterilizing contaminated instruments is an essential component of effective infection control in clinical practices to ensure protection of patients and health care professionals. In dental settings, the most commonly used and recommended sterilization method is steam (autoclaving). ${ }^{1}$ Other options include chemiclaves using chemical vapor sterilization and dry heat sterilizers. Sterilization procedures should be regularly monitored as recommended by the Centers for Disease Control and Prevention (CDC) ${ }^{1}$ and the Association for the Advancement of Medical Instrumentation (ANSI/AAMI) ${ }^{2}$ to verify the effectiveness of sterilization. Biological indicators (BIs) are the most 
accepted means of monitoring sterilization because they assess the process directly by killing known highly resistant microorganisms, thus offering greater sterility assurance than mechanical or chemical indicators. ${ }^{1}$ The resistance of microorganisms to sterilization ranges from low (lipids and medium-sized viruses, such as hepatitis B and human immunodeficiency virus) to high. Other than prions, the most resistant microorganisms are bacterial spores and these are used to test the ability of the sterilization process to kill microorganisms. ${ }^{3}$ The specific spore selected in BIs depends on the type of sterilizer. For steam autoclaves, Geobacillus stearothermophilus (formerly Bacillus stearothermophilus) is used while Bacillus atrophaeus (formerly Bacillus subtilis) is utilized for dry heat sterilizers. ${ }^{1,4}$ Spore strips in the chamber and SCBIs impregnated with the resistant spores are among the most widely used BIs for the validation and monitoring of sterilization in dental settings. ${ }^{5-9}$

According to CDC guidelines, BIs should be used for routine sterilizer monitoring at least weekly, but preferably every day that the sterilizer is in use. ${ }^{1}$ Additionally, BIs must be used to monitor every load containing implants, for sterilizer qualification testing after sterilizer installation, relocation, malfunctions, major repairs, and after sterilization process failures. Furthermore, ANSI/AAMI states that "product testing should always be done when major changes are made in packaging, product or load configuration, or materials, such as dimensional changes, weight changes, or changes in the type of packaging or wrapper used."2

While such practices are compulsory by legislation in the United States and other developed countries, they continue to be poorly regulated in developing countries. In a previous survey evaluating knowledge, attitude, and behavior of Lebanese dentists relative to infectious diseases, the overall compliance with infection control measures has been demonstrated to be inadequate in the private dental sector. ${ }^{10}$ Autoclaves were reported to be the preferred means of sterilization in nearly $65 \%$ of the participating clinics, but dry heat sterilizers continued to be used among the respondents (35.0\%). No documentation is currently available relative to the biologic monitoring of sterilization in dental practices in Lebanon.

The objectives of the present study were to (1) survey the sterilization practices in a representative sample of private dental offices in Lebanon and (2) evaluate the incidence and potential causes of sterilization failures in these clinics.

\section{MATERIALS AND METHODS}

\section{Study Sample}

A sample of private dental offices was drawn from the database of virtually all dentists registered in the Lebanese
Dental Associations and was provided by the Associations boards. The participating dentists were drawn from various sociodemographic and professional contexts regardless of age, gender, type, or years of practice.

The sample size was calculated during the planning phase of the study using the sampling formula:

$$
\text { Sample }=\frac{N z^{2} p q}{d^{2}(N-1)+z^{2} p q}
$$

where

- $\mathrm{N}=$ the total population of dentists registered in the Lebanese Dental Associations (5004 dentists);

- $\mathrm{p}=$ estimated failure rate $(10 \%)$;

- $\mathrm{q}=1-\mathrm{p}$;

- $\mathrm{z}=$ the number of standard deviation away from the sample proportion $(z=1.96$ for a $95 \%$ confidence interval);

- $\mathrm{d}=$ half of the width of the confidence interval of the sample proportion $\mathrm{p}(\mathrm{d}=4 \%$ and confidence interval $=10 \pm 4 \%$, which means $6 \% \leq \mathrm{p} \leq 14 \%$ ).

The sample size considered representative for the survey was 207 representing $4.14 \%$ of the total number of Lebanese dentists with 135 using autoclaves and 72 owning ovens. This ratio was based on the findings of a previous survey where $65 \%$ of the Lebanese private dental offices operated autoclaves vs 35\% that used ovens. ${ }^{10}$ Assuming a response rate of approximately $37 \%$ in the Lebanese private dental sector, a list of 560 dentists was selected according to a proportional stratified random sampling to ensure equitable representation of the five geographic regions of Lebanon. ${ }^{10}$

\section{STUDY DESIGN}

Dental practices were pre-screened by calling the dentists and asking about their willingness to participate in the survey and have the performance of their sterilizers tested. The dentists were informed that the results of the study would be published but that the survey responses and results of the biologic monitoring would be kept confidential. When a dentist did not respond or declined to take part in the study, he/she was substituted by the following dentist on the list. Dentists who confirmed their participation were asked about the type of sterilizer they use in their practice. Enrollment was continued until the desired sample size was reached.

Sealed envelopes including an introductory letter explaining the goals of the study, a printed 13-item short questionnaire, three SCBIs, and instructions on how to use them were delivered personally to the selected dentists between November 3, 2016 and October 9, 2017. The participants returned the completed questionnaires and indicators within one week for evaluation and incubation. 
This research was conducted in full accordance with the World Medical Association Declaration of Helsinki.

\section{Questionnaire}

Given the lack of a standardized validated questionnaire to assess sterilization practices by dentists, a pilot survey was conducted on a random sample of 30 dentists working in private clinics to ensure practicability, relevance, and proper interpretation of the questions. The responses from the pilot test were analyzed and the questionnaire was modified according to the feedback obtained.

In addition to four questions related to demographic and professional status (gender, type of practice, i.e., specialist $v s$ general practitioner, years of experience, and region of practice), the questionnaire comprised nine questions covering sterilization-related issues including brand name, type, and age of the sterilizer used, person in charge of routine sterilization procedures in the dental practice (dentist or dental assistant), frequency of use of the sterilizer, routinely applied sterilization parameters, frequency of professional maintenance, frequency, and type of routine monitoring of sterilization (physical indicators, chemical indicators, and biologic indicators). Dentists who returned the forms with some blank answers were re-contacted over the phone and asked about the missing details.

The sterilization cycles that were validated for specific sterilization accessories (i.e., BIs, trays/containers, wraps), cleared by the US Food and Drug Administration and reported by the CDC (2017) ${ }^{1}$ and ANSI/AAMI (2017), ${ }^{2}$ are summarized in Table 1 . These figures were used to categorize the sterilization parameters reported in the questionnaires as correct or incorrect.

\section{Biologic Monitoring}

The three SCBIs sent to each participant included the spores of G. stearothermophilus for the autoclaves (Attest ${ }^{\mathrm{TM}}$ Biological Indicators, 3M, St. Paul, Minnesota, USA) and B. atrophaeus for the dry heat sterilizers (DriAmp ${ }^{\mathrm{TM}}$, MesaLabs, Bozeman, Montana, USA). Two of the three spore-containing vials were labeled "TEST" while the third was labeled "CONTROL." The dentists were instructed to perform the biologic testing during a normal sterilization cycle and place one test SCBI unit in the middle, and one in the front of the autoclave near the door of the sterilizer chamber. These two test SCBIs were to be placed among the instruments to be sterilized, with or without wrapping as routinely performed. The third SCBI unit was not to be processed and served as positive control for bacterial growth. The dentists were asked to allow the sterilized instruments and test SCBIs to cool for at least 10 minutes for the autoclaves and 30 minutes for the ovens at the end of the sterilization cycle. The SCBIs were labeled with a self-adhesive tag including the dentist's code and processing date and were refrigerated until incubation was possible. The returned three SCBI units were collected from the dental offices and examined for the type of packaging (wrapped or unwrapped). For autoclaves, the samples were placed into a $56^{\circ} \mathrm{C}$ dry block incubator (3M) and evaluated at 24,48 , and 72 hours for color change according to the manufacturer's recommendations. For ovens, the SCBIs were incubated in a microbiological incubator adjusted to 36 to $38^{\circ} \mathrm{C}$ using the Releasat ${ }^{\circledR}$ medium (Mesa Labs) and results read at 72 hours and 7 days. Testing manipulations for the DriAmp ${ }^{\mathrm{TM}}$ BIs were performed under aseptic conditions within the confines of a laminar flow hood in a microbiology laboratory (St. Marc Medical Laboratory, Beirut, Lebanon) to avoid false-positive readings. Sterilization failure was recorded when color change toward yellow occurred after incubation (SCBI test positive), while absence of any growth represented successful sterilization (SCBI test negative).

\section{Statistical Analysis}

The answers were processed using the Statistic Package for the Social Sciences (IBM SPSS for Windows, Version 20.0; IBM Corp., Armonk, New York, USA). Descriptive statistics with means, standard deviations, and frequency distributions were generated for all variables. The outcome measure (dependent variable) of the sterilization process was dichotomous and expressed as "failure" or "success." Bivariate analyses were performed using t-test to assess the effect of continuous independent variables, i.e., sterilizer age on sterilization failures, and chi-square analysis when the independent variable was categorical (gender, type of practice, years of practices, sterilizer type, person in charge of sterilization, number of cycles per week, correct or incorrect temperature/time ratio, frequency of professional maintenance, and frequency of monitoring). Fisher's exact test was applied when

Table 1: Proposed validated sterilization cycles with temperature and exposure time for dry heat ovens ${ }^{1}$ and autoclaves ${ }^{2}$

\begin{tabular}{|c|c|c|c|c|c|c|c|c|c|c|c|c|c|c|c|}
\hline & \multicolumn{12}{|c|}{ Steam autoclaves } & \multirow{2}{*}{\multicolumn{3}{|c|}{ Dry heat ovens }} \\
\hline & \multicolumn{6}{|c|}{ Gravity displacement } & \multicolumn{6}{|c|}{ Dynamic air removal } & & & \\
\hline & \multicolumn{3}{|c|}{ Wrapped } & \multicolumn{3}{|c|}{ Unwrapped } & \multicolumn{3}{|c|}{ Wrapped } & \multicolumn{3}{|c|}{ Unwrapped } & \multicolumn{3}{|c|}{ Wrapped or unwrappeo } \\
\hline Temperature $\left({ }^{\circ} \mathrm{C}\right)$ & 121 & 132 & $134 / 135$ & 121 & 132 & $134 / 135$ & 121 & 132 & $134 / 135$ & 121 & 132 & $134 / 135$ & 150 & 160 & 170 \\
\hline Time (minutes) & 30 & 15 & 10 & 30 & 10 & 3 & 20 & 4 & 3 & 15 & 3 & 3 & 150 & 120 & 60 \\
\hline
\end{tabular}


the assumptions of chi-square test were violated (more than $20 \%$ of the expected counts were less than 5 and all individual expected counts were 1 or greater). The level of significance was set at $\mathrm{p}<0.05$.

\section{RESULTS}

Out of the 560 dentists initially contacted over the phone, 230 agreed to participate and received the study-related envelopes. Out of these, 211 returned the study packages, yielding a response rate of $37.7 \%$. Four returned processed SCBIs were damaged ( 2 crushed and 2 melted) and 2 SCBIs were not included in the returned packages. These six offices were excluded from the study. Forty-five dentists had to be recontacted to retrieve the missing information and fill in the blanks in the questionnaires. Therefore, final data were obtained from 205 fully completed questionnaires and corresponding SCBI test results (134 autoclaves and 71 ovens).

Table 2 summarizes the distribution of the 205 participating dentists according to gender and type, years and region of practice. The sample included 130 male (63.4\%) and 75 female $(36.6 \%)$ dentists with an average period in practice of $16.8 \pm 9.0$ years. Most of the dentists were general practitioners (63.4\%), and practiced in the Mount Lebanon region (44.9\%).

Table 3 summarizes sterilization-related data obtained from dentists using steam sterilizers. The reported type of autoclaves coupled with the brand name confirmed that the most commonly used autoclaves were dynamic air removal (69.4\%) and that fewer offices had gravity displacement $(30.6 \%)$. The tested autoclaves had a mean

Table 2: Demographic and professional distribution of the participating dentists in private dental practices in Lebanon (2016-2017)

\begin{tabular}{lll}
\hline $\begin{array}{l}\text { Demographic and } \\
\text { professional variables }\end{array}$ & $\begin{array}{l}\text { Number of } \\
\text { respondents }\end{array}$ & Percent \\
\hline $\begin{array}{l}\text { Gender } \\
\text { Male }\end{array}$ & 130 & 63.4 \\
Female & 75 & 36.6 \\
$\begin{array}{l}\text { Type of practice } \\
\text { General practitioner }\end{array}$ & & \\
Specialist & 130 & 63.4 \\
Years in practice & 75 & 36.6 \\
$<5$ & & \\
5-10 & 14 & 6.8 \\
11-20 & 55 & 26.8 \\
$>$ 20 & 64 & 31.2 \\
Region of practice & 72 & 35.1 \\
Beirut & & \\
Beqaa & 46 & 22.4 \\
Mount Lebanon & 19 & 9.3 \\
South Lebanon and Nabatieh & 92 & 44.9 \\
North Lebanon & 24 & 11.7 \\
\hline
\end{tabular}

age of $10.5 \pm 6.9$ years ( $1-30$ years) with $17.7 \pm 6.8$ years for the gravity displacement and $7.3 \pm 3.9$ years for the dynamic air removal autoclaves. In the majority of practices $(61.9 \%)$, the dental assistants performed the routine sterilization procedures. In nearly $75 \%$ of the dental offices, sterilization cycles were run 4 to 6 times per week. Adequate temperature/time ratios were applied in $97 \%$ of the autoclaves. More than $80 \%$ of the surveyed dentists reported having professional maintenance performed only in case of malfunction. Few practices (17.9\%) indicated having preventive maintenance scheduled on yearly basis. Routine monitoring of sterilizer efficacy was rarely performed $(8.2 \%)$ and was mostly conducted using physical indicators.

Results of oven-related questionnaires are summarized in Table 4. All participating dentists used static air ovens with an average age of $12.9 \pm 8.1$ years (1-33 years).

Table 3: Summary of sterilization-related data obtained from the participating Lebanese private dental clinics using autoclaves (2016-2017)

\begin{tabular}{|c|c|c|}
\hline $\begin{array}{l}\text { Questions related to sterilization } \\
\text { practices }\end{array}$ & $\begin{array}{l}\text { Number of } \\
\text { respondents }\end{array}$ & Percent \\
\hline \multicolumn{3}{|l|}{ Type of autoclave } \\
\hline Dynamic air removal & 93 & 69.4 \\
\hline Gravity displacement & 41 & 30.6 \\
\hline \multicolumn{3}{|l|}{ Age of autoclave (years) } \\
\hline $0-5$ & 41 & 30.6 \\
\hline $6-10$ & 45 & 33.6 \\
\hline $11-20$ & 33 & 24.6 \\
\hline$>20$ years & 15 & 11.2 \\
\hline \multicolumn{3}{|l|}{ Person in charge of sterilization } \\
\hline The dentist him/herself & 51 & 38.1 \\
\hline The dental assistant & 83 & 61.9 \\
\hline \multicolumn{3}{|l|}{$\begin{array}{l}\text { Frequency of autoclave use (cycles } \\
\text { per week) }\end{array}$} \\
\hline $1-3$ & 17 & 12.7 \\
\hline $4-6$ & 101 & 75.4 \\
\hline $7-10$ & 13 & 9.7 \\
\hline$>10$ & 3 & 2.2 \\
\hline \multicolumn{3}{|c|}{ Autoclave parameters used routinely } \\
\hline Correct ratio temperature/time & 130 & 97.0 \\
\hline Incorrect ratio temperature/time & 4 & 3 \\
\hline \multicolumn{3}{|c|}{$\begin{array}{l}\text { Frequency of autoclave professional } \\
\text { maintenance }\end{array}$} \\
\hline Yearly & 24 & 17.9 \\
\hline Only when problems & 110 & 82.1 \\
\hline \multicolumn{3}{|l|}{$\begin{array}{l}\text { Frequency of regular monitoring of } \\
\text { sterilization }\end{array}$} \\
\hline Always & 11 & 8.2 \\
\hline Occasionally & 37 & 27.6 \\
\hline Rarely & 86 & 64.2 \\
\hline \multicolumn{3}{|c|}{$\begin{array}{l}\text { Type of tests for regular monitoring of } \\
\text { sterilization }\end{array}$} \\
\hline Physical indicators & 108 & 80.6 \\
\hline Chemical indicators & 25 & 18.7 \\
\hline Biological indicators & 1 & 0.7 \\
\hline
\end{tabular}


Table 4: Summary of sterilization-related data obtained from the participating Lebanese private dental clinics using dry heat sterilizers (2016-2017)

\begin{tabular}{|c|c|c|}
\hline Variables related to sterilization practices & $\begin{array}{l}\text { Number of } \\
\text { respondents }\end{array}$ & Percent \\
\hline \multicolumn{3}{|l|}{ Type of oven } \\
\hline Static air & 71 & 100 \\
\hline Forced air & 0 & 0 \\
\hline \multicolumn{3}{|l|}{ Age of oven (years) } \\
\hline $0-5$ & 16 & 22.5 \\
\hline $6-10$ & 16 & 22.5 \\
\hline $11-20$ & 27 & 38.0 \\
\hline$>20$ & 12 & 16.9 \\
\hline \multicolumn{3}{|l|}{ Person in charge of oven } \\
\hline The dentist him/herself & 28 & 39.4 \\
\hline The dental assistant & 43 & 60.6 \\
\hline \multicolumn{3}{|l|}{ Frequency of oven use (cycles per week) } \\
\hline $1-3$ & 8 & 11.3 \\
\hline $4-6$ & 47 & 66.2 \\
\hline $7-10$ & 10 & 14.1 \\
\hline$>10$ cycles per week & 6 & 8.5 \\
\hline \multicolumn{3}{|l|}{ Oven parameters used routinely } \\
\hline Correct ratio temperature/time & 57 & 80.3 \\
\hline Incorrect ratio temperature/time & 14 & 19.7 \\
\hline \multicolumn{3}{|l|}{$\begin{array}{l}\text { Frequency of oven professional } \\
\text { maintenance }\end{array}$} \\
\hline Yearly & 10 & 14.1 \\
\hline Only when problems & 61 & 85.9 \\
\hline \multicolumn{3}{|l|}{$\begin{array}{l}\text { Frequency of regular monitoring of } \\
\text { sterilization }\end{array}$} \\
\hline Always & 12 & 16.9 \\
\hline Occasionally & 21 & 29.6 \\
\hline Rarely & 38 & 53.5 \\
\hline \multicolumn{3}{|l|}{$\begin{array}{l}\text { Type of tests for regular monitoring of } \\
\text { Sterilization }\end{array}$} \\
\hline Physical indicators & 64 & 90.1 \\
\hline Chemical indicators & 7 & 9.9 \\
\hline Biological indicators & 0 & 0 \\
\hline
\end{tabular}

Sterilization-related data reported with ovens were similar to those found in autoclave users. Assistants were primarily responsible of the routine sterilization procedures $(60.6 \%)$ and sterilization cycles were predominantly run 4 to 6 times per week $(66.2 \%)$. The routinely applied temperature/time ratio was correct in $80.3 \%$ of the oven users. Alow rate of regular preventive professional maintenance was reported $(14.1 \%)$. Routine sterilizer efficacy testing was infrequent $(29.6 \%)$ to rare $(53.5 \%)$ and physical indicators were mainly used for the monitoring process (90.1\%).

The characteristics of failed autoclaves and ovens are reported in Tables 5 and 6.10 out of the 134 tested autoclaves had positive spore tests yielding a sterilization failure rate of $7.5 \%$. The failed autoclaves had a mean age of $16.5 \pm 5.6$ years $v$ s the successful autoclaves which had an average age of $10.0 \pm 6.8$ years. Independent sample t-test analysis showed that the difference was statistically significant $(\mathrm{p}=0.004)$. More gravity displacement autoclaves failed than dynamic air removal (17.1 vs 3.2\%; $\mathrm{p}=0.009$ ) (Table 7). In 95.4\% of the successful autoclaves, a correct ratio temperature/time was used. All of the autoclaves with incorrect ratios failed their sterilization cycles.

Ovens were associated with a higher rate of failures $(16.9 \%)$ than autoclaves $(7.5 \%)(p=0.038)$ (Table 7$)$. The mean age of the failed ovens was $18.9 \pm 8.8$ years vs 11.6 \pm 7.5 years for the successful ones, the difference being statistically significant $(\mathrm{p}=0.004)$. All oven failures were associated with incorrect temperature/time ratios (Table 7). Two ovens with incorrect operational parameters $\left(180^{\circ} \mathrm{C}\right.$ for 50 minutes and $160^{\circ} \mathrm{C}$ for 110 minutes) passed successfully the spore test.

When sterilization data obtained from autoclaves and ovens were considered separately or jointly (Table 7), no statistically significant relationships were demonstrated between percentage failures and the demographic/ professional variables (gender, type of practice, and years

Table 5: Characteristics of failed autoclaves and related sterilization data

\begin{tabular}{llllllll}
\hline $\begin{array}{l}\text { Sterilization } \\
\text { failure }\end{array}$ & $\begin{array}{l}\text { Type of } \\
\text { atoclave }\end{array}$ & $\begin{array}{l}\text { Age of } \\
\text { autoclave }\end{array}$ & $\begin{array}{l}\text { Number of } \\
\text { cycles per } \\
\text { week }\end{array}$ & $\begin{array}{l}\text { Correct or incorrect } \\
\text { ratio temperature/ } \\
\text { time }\end{array}$ & $\begin{array}{l}\text { Frequency of } \\
\text { professional } \\
\text { maintenance }\end{array}$ & $\begin{array}{l}\text { Frequency } \\
\text { of regular } \\
\text { monitoring }\end{array}$ & $\begin{array}{l}\text { Type of regular } \\
\text { sterilization } \\
\text { monitoring }\end{array}$ \\
\hline 1 & GD & 16 & 5 & Correct & OWP & Rarely & Physical \\
2 & GD & 30 & 4 & Incorrect & OWP & Rarely & Physical \\
3 & GD & 14 & 6 & Correct & OWP & Rarely & Physical \\
4 & GD & 15 & 5 & Correct & OWP & Occasionally Physical & Physical \\
5 & GD & 18 & 7 & Incorrect & OWP & Rarely & Physical \\
6 & GD & 19 & 4 & Incorrect & OWP & Rarely & Physically Physical \\
7 & GD & 17 & 4 & Incorrect & OWP & Occasionally & Physical \\
8 & DAR & 11 & 5 & Correct & OWP & Rarely & Phys \\
9 & DAR & 16 & 6 & Correct & OWP & Rarely & Physical \\
10 & DAR & 9 & 6 & Correct & OWP & Rarely & Physical \\
\hline
\end{tabular}

GD: Gravity displacement; DAR: Dynamic air removal; OWP: Only when problems 
Table 6: Characteristics of failed dry heat sterilizers and related sterilization data

\begin{tabular}{cllllll}
\hline $\begin{array}{l}\text { Sterilization } \\
\text { failure }\end{array}$ & $\begin{array}{l}\text { Age of } \\
\text { oven }\end{array}$ & $\begin{array}{l}\text { Number of } \\
\text { cycles per } \\
\text { week }\end{array}$ & $\begin{array}{l}\text { Correct or incorrect } \\
\text { ratio temperature/ } \\
\text { time }\end{array}$ & $\begin{array}{l}\text { Frequency of } \\
\text { professional } \\
\text { maintenance }\end{array}$ & $\begin{array}{l}\text { Frequency } \\
\text { of regular } \\
\text { monitoring }\end{array}$ & $\begin{array}{l}\text { Type of regular } \\
\text { sterilization } \\
\text { monitoring }\end{array}$ \\
\hline 1 & 20 & 3 & Incorrect & OWP & Rarely & Physical \\
2 & 15 & 7 & Incorrect & OWP & Rarely & Physical \\
3 & 33 & 7 & Incorrect & OWP & Rarely & Physical \\
4 & 9 & 3 & Incorrect & OWP & Rarely & Physical \\
5 & 25 & 3 & Incorrect & OWP & Rarely & Physical \\
6 & 12 & 3 & Incorrect & OWP & Rarely & Physical \\
7 & 30 & 5 & Incorrect & OWP & Occasionally & Physical \\
8 & 18 & 3 & Incorrect & OWP & Rarely & Physical \\
9 & 20 & 4 & Incorrect & Yearly & Always & Physical \\
10 & 5 & 4 & Oncorrect & OWP & Rarely & Physical \\
11 & 12 & 5 & Incorrect & Rarely & Physical \\
12 & 28 & 5 & Incorrect & & Always & Physical \\
\hline
\end{tabular}

OWP: Only when problems

Table 7: Bivariate analysis reporting the effect of sterilization-related variables on sterilization failures with autoclaves, ovens, and pooled sterilizers

\begin{tabular}{|c|c|c|c|c|c|c|}
\hline & \multicolumn{2}{|c|}{ Autoclaves } & \multicolumn{2}{|c|}{ Ovens } & \multicolumn{2}{|c|}{ Both } \\
\hline & $n(\%)$ & $p$-value & $n(\%)$ & $p$-value & $n(\%)$ & $p$-value \\
\hline \multicolumn{7}{|l|}{ Category of sterilizer } \\
\hline Autoclave & - & - & - & - & $10(7.5 \%)$ & $0.038^{*}$ \\
\hline Oven & - & - & - & - & $12(16.9 \%)$ & \\
\hline \multicolumn{7}{|l|}{ Type of sterilizer } \\
\hline Dynamic air removal autoclave & $3(3.2 \%)$ & $0.009^{*}$ & - & - & $3(3.2 \%)$ & $0.007^{*}$ \\
\hline Gravity displacement autoclave & $7(17.1 \%)$ & - & - & - & $7(17.1 \%)$ & \\
\hline Static air oven & - & - & - & - & $12(16.9 \%)$ & \\
\hline \multicolumn{7}{|l|}{ Person in charge of sterilization } \\
\hline The dentist him/herself & $1(2 \%)$ & 0.088 & $4(14.3 \%)$ & 0.753 & $5(6.3 \%)$ & 0.107 \\
\hline The dental assistant & $9(10.8 \%)$ & - & $8(18.6 \%)$ & - & $17(13.5 \%)$ & - \\
\hline \multicolumn{7}{|c|}{ Frequency of autoclave use (cycles per week) } \\
\hline $1-3$ & $0(0 \%)$ & 0.425 & $5(62.5 \%)$ & $0.001^{*}$ & $5(20 \%)$ & 0.279 \\
\hline $4-6$ & $9(8.9 \%)$ & - & $5(10.6 \%)$ & - & $14(9.5 \%)$ & - \\
\hline$>6$ & $1(6.3 \%)$ & - & $2(12.5 \%)$ & - & $3(9.4 \%)$ & - \\
\hline \multicolumn{7}{|l|}{ Ratio temperature/time } \\
\hline Incorrect & $4(100 \%)$ & $0.000^{*}$ & $12(85.7 \%)$ & $0.000^{*}$ & $16(88.9 \%)$ & $0.000^{*}$ \\
\hline Correct & $6(4.6 \%)$ & - & $0(0 \%)$ & - & $6(3.2 \%)$ & - \\
\hline \multicolumn{7}{|c|}{ Frequency of professional maintenance } \\
\hline Yearly & $0(0 \%)$ & 0.208 & $2(20 \%)$ & 0.673 & $2(5.9 \%)$ & 0.543 \\
\hline Only when problems & $10(9.1 \%)$ & - & $10(16.4 \%)$ & - & $20(11.7 \%)$ & \\
\hline \multicolumn{7}{|l|}{ Frequency of regular monitoring } \\
\hline Always & $0(0 \%)$ & 0.464 & $2(16.7 \%)$ & 0.178 & $2(8.7 \%)$ & 0.210 \\
\hline Occasionally & $2(5.4 \%)$ & - & $1(4.8 \%)$ & - & $3(5.2 \%)$ & - \\
\hline Rarely & $8(9.3 \%)$ & - & $9(23.7 \%)$ & - & $17(13.7 \%)$ & - \\
\hline
\end{tabular}

Fisher's exact test was used in all cross-tabulations of autoclave data and dry heat data when analyzed separately, and in pooled data when comparing the effect of frequency of sterilizer maintenance and the effect of correct temperature/time ratio on failure; *statistically significant

of practices) or sterilization-related variables (person in charge of sterilization, frequency of professional maintenance and regular monitoring). Sterilization failure was significantly affected by the application of correct or incorrect temperature/time ratios in autoclaves, ovens, and pooled sterilizers $(p=0.000)$ (Table 7).
All dental offices with failed sterilizers were immediately notified over the telephone. Whenever possible, the person responsible for sterilization was informed about the potential reasons for sterilization failure and given advice on how to improve the sterilizer performance. Unfortunately, the nonsterile instrument loads associated with cycle failures could not be recalled because of the 
time lag between the sterilization cycle and availability of the spore tests results.

\section{DISCUSSION}

Data related to sterilizers performance using spore tests among dentists in developed countries, such as the USA,${ }^{11-17}$ Canada, ${ }^{18}$ Norway, ${ }^{6,19}$ Denmark, ${ }^{5}$ Spain, ${ }^{20}$ and Germany, ${ }^{21,22}$ are two to four decades old for the most part, confirming that quality assurance of sterilization has become an integral and highly protocoled part of practice in these countries. Related information in developing countries is somewhat more recent, indicating that this issue has only lately started to gain serious interest. ${ }^{7,9,23-26}$

The present study demonstrated that routine sterilization monitoring is not frequently performed in the Lebanese private dental sector $(8.2 \%$ for the autoclaves and $16.9 \%$ of the ovens). Physical monitoring through observation of gauges or monitors showing temperature, time, and pressure during the operational cycles seems to be the preferred method in the studied sample $(80.6 \%$ for autoclaves and $90.1 \%$ for ovens). Internal chemical monitoring through the use of chemical indicators that change color at specific temperature and/or time cycles is less commonly used (18.7\% for autoclaves and 9.9\% for ovens). These two methods confirm that specific exposure conditions were met and that the sterilant has penetrated to the point of placement of the indicator in the pack without the absolute guarantee of effective sterilization. BIs monitor the interaction of all sterilization parameters and verify that the conditions at the BI location within the load were adequate to kill resistant spores and provide optimal sterility assurance. Although regular spore testing in dental practices is incorporated as a law requirement in quality control procedures in most developed countries, BIs continue to be rarely or never used by the private Lebanese dentists $(0.7 \%$ for autoclaves and $0 \%$ for ovens).

In the present Lebanese sample, sterilization failure rate with autoclaves amounted to $7.5 \%$, which compares favorably with recently reported data on the effectiveness of autoclaves using spore tests in dental practices in developing countries, such as Mexico (6.7 and 21\%) $)^{7,26}$ and Brazil $(8.3 \%){ }^{27}$

The failed autoclaves in the present investigation had a significantly higher mean age than the successful ones $(16.5 \pm 5.6$ and $10.0 \pm 6.8$ years respectively). There were more failed gravity displacement autoclaves than dynamic air removal (17.1 vs 3.2\%; $p=0.009$ ). In a study evaluating the outcome of sterilization by steam autoclaves in Danish dental offices, the two parameters brand and age of autoclaves were not demonstrated to be implicated in sterilization failure. ${ }^{5}$ It should be noted, however, that the mean age of autoclaves in the Danish sample was only 8.9 vs 17.7 years for the gravity displacement autoclaves of the present study. ${ }^{5}$ Although regression analysis could not be performed to assess the predictor variables of sterilization failure due to the small number of positive spore tests, it can be suggested that inadequate sterilizers performance could, at least partly, be attributed to old age, especially when it is coupled with infrequent routine professional maintenance.

In nearly $95 \%$ of the successful autoclaves, a correct ratio temperature/time was applied. Furthermore, all autoclaves with incorrect temperature/time settings failed. This tendency confirms previously published conclusions that most sterilization failures are due to operator error and not to inherent defects in the sterilization devices. ${ }^{20}$ In 6 out of the 10 autoclave failures in the present study, the dentists reported that correct temperature/time ratio was reached during the sterilization cycles. Although these two parameters can be readily observed by checking the sterilizer gauges, monitors, or computer displays, the third parameter "pressure" is more difficult to confirm through physical monitoring and is better supported by printouts. Other variables not investigated in the present study, such as overloading of the sterilizer, lack of separation between packages/cassettes, or improper packaging material and technique could have contributed to the sterilization process failures. The other investigated sterilization-related parameters, i.e., person in charge of routine sterilization, frequency of professional maintenance, and routine monitoring were not associated with higher autoclave failure rates. These findings are in accordance with the study of Acosta-Gío et $\mathrm{al}^{7}$ in which lack of routine maintenance and sterilizer monitoring were not found to be related to sterilization failures.

Dry heat ovens continue to be used in the private Lebanese dental sector and represent approximately one-third of the overall sterilizers. ${ }^{10}$ The 12 failed ovens were linked with users who reported inadequate temperature/time ratios, indicating that failure to inactivate bacterial spores can be reliably attributed to human error in accordance with the findings of de Nardo et al. ${ }^{9}$ Lack of knowledge of the correct temperature/ time exposure levels required for efficient sterilization is often associated with the use of dry heat sterilizers. ${ }^{28}$ Two ovens passed successfully the spore test despite the application of incorrect operational parameters $\left(180^{\circ} \mathrm{C}\right.$ for 50 minutes and $160^{\circ} \mathrm{C}$ for 110 minutes). Although $180^{\circ} \mathrm{C}$ may not be recommended for dental instruments and the exposure time of 110 minutes is 10 minutes short of the recommended figures at $160^{\circ} \mathrm{C}$, it should be noted that these values still fall within the range of the minimal 
kill time calculated according to current International Organization for Standardization standards. ${ }^{29}$

In the present study, sterilization failure rate was greater in ovens than in autoclaves. This finding is in agreement with the trend observed in dental practices in Mexico (6.7\% for the autoclaves vs 10.7\% for ovens) $)^{7}$ and Brazil ( $0 \%$ for autoclaves vs $25 \%$ for ovens), ${ }^{9}$ (8.3\% for autoclaves and $21.5 \%$ for ovens $){ }^{27}(0 \%$ for autoclaves and $12 \%$ for ovens). ${ }^{28}$ Although the application of incorrect settings temperature/time was identified as the main reason for failures in both autoclaves and ovens, steam sterilizers, especially the newer generation autoclaves, are more sophisticated devices with several automated parameter settings and could therefore, minimize human error in parameters selection. In addition, newer autoclaves are equipped with alarm systems indicating that sterilization parameters were not reached in the allocated time and prompting corrective actions.

The Attest ${ }^{\mathrm{TM}}$ indicators used in the present study are self-contained, i.e., contain both the dry spore strip and the growth medium. This design minimizes the possibility of contamination which may occur with spore strips in glassine envelopes when they are transferred to the growth medium producing a false-positive result. This type of BI has been demonstrated to be highly reliable for vacuum-assisted and gravity displacement steam sterilization cycles with rare false-negative results. ${ }^{30}$ It is noteworthy that a negative $\mathrm{BI}$ does not prove that all items in the load are sterile or that they were all exposed to adequate sterilization conditions.

One of the limitations of the present study is related to the use of one single monitoring test per sterilizer. This might have resulted in underestimation of the true incidence of sterilization failures since more frequent testing is likely to be associated with increased failure detection rate. ${ }^{7}$ A second drawback is the limited number of sterilization-based questions included in the survey. Sterilization process failures occur for many reasons, such as sterilizer malfunction, incorrect settings or cycle selection, improper disinfection, packaging, loading, storage, and others. Future larger scale studies with broader questionnaires should be conducted to investigate operator- and sterilizer-related factors associated with sterilization failures and identify barriers for the generalized implementation of CDC sterilization guidelines in Lebanon.

\section{CONCLUSION}

The present study highlights the results of sterilization practices and sterilizers performance in the private Lebanese dental sector in 2016 to 2017 and provides the basis for prospective comparisons assessing potential future changes. The present findings should be considered to enhance general awareness of the importance of routine monitoring of the sterilizing equipment and understanding some of the potential causes of sterilization failures. Some tangible steps should be considered by the Ministry of Health in collaboration with the Lebanese dental associations and universities and regulated under a formalized legal legislation: (1) increasing infection control-related continuing education requirements and mandatory courses/workshops; (2) development and distribution of sterilization manuals that incorporate updated guidelines and recommendations for dental practices; (3) instigate certain practices, such as sterilization monitoring and confirmation of sterilization efficiency through documented printouts as a prerequisite to practice or license renewal; (4) continuous monitoring of private dental clinics to supervise adherence to sterilization CDC guidelines.

\section{REFERENCES}

1. Rutala, WA.; Weber, DJ.; the Healthcare Infection Control Practices Advisory Committee (HICPAC). Guideline for disinfection and sterilization in healthcare facilities. Clifton Road Atlanta (GA): CDC; 2008. p. 58-79. [cited 2017 Feb 15]. Available from: https://www.cdc.gov/infectioncontrol/ guidelines/disinfection/.

2. Association for the Advancement of Medical Instrumentation. ANSI/AAMI:ST79/2017: comprehensive guide to steam sterilization and sterility assurance in health care facilities. Arlington (VA): AAMI; 2017. p. 79-101. Available from: https:/ / standards.aami.org/higherlogic/ws/.../Public\%20 review\%20CDV-2\%20ST79.pdf

3. Schneider PM, Reich RR, Kirckof SS, Foltz WG. Performance of various steam sterilization indicators under optimum and sub-optimum exposure conditions. Am J Infect Control 2005 Jun;33(5 Suppl 2):S55-S67.

4. Sella SR, Vandenberghe LP, Soccol CR. Bacillus atrophaeus: main characteristics and biotechnological applications-a review. Crit Rev Biotechnol 2015 Oct;35(4);533-545.

5. Scheutz F, Reinholdt J. Outcome of sterilization by steam autoclaves in Danish dental offices. Scand J Dent Res 1988 Apr;96(2):167-170.

6. Skaug N. Proper monitoring of sterilization procedures used in oral surgery. Int J Oral Surg 1983 Jun;12(3):153-158.

7. Acosta-Gío AE, Mata-Portuguez VH, Herrero-Farías A, Sánchez Pérez L. Biologic monitoring of dental office sterilizers in Mexico. Am J Infect Control 2002 May;30(3):153-157.

8. Kohn WG, Collins AS, Cleveland JL, Harte JA, Eklund KJ, Malvitz DM. Guidelines for infection control in dental health-care settings-2003. MMWR Recomm Rep 2003 Dec;52(RR17):1-61.

9. de Nardo AP, Romano TG, Dias AGA, Guimarães G. Sterilization in the dental private sector. RGO—Rev Gaúcha Odontol 2013 Jan-Mar;61(1):47-53.

10. Dagher J, Sfeir C, Abdallah A, Majzoub Z. Infection control measures in private dental clinics in Lebanon. Int J Dent 2017 May;2017:5057248. 
11. Simonsen RJ, Schachtele CF, Joos RW. An evaluation of sterilization by autoclave in dental offices. J Dent Res 1979 Jan;58:400.

12. Palenik CJ, King TN, Newton CW, Miller CH, Koerber LG. A survey of sterilization practices in selected endodontic offices. J Endod 1986 Jan;12(5):206-209.

13. Nickerson A, Bhuta P, Orton G, Alvin B. Monitoring dental sterilizers' effectiveness using biological indicators. J Dent Hyg 1990 Feb;64(2):69-73.

14. Hastreiter RJ, Molinari JA, Falken MC, Roesch MH, Gleason MJ, Merchant VA. Effectiveness of dental office instrument sterilization procedures. J Am Dent Assoc 1991 Oct;122(10):51-56.

15. Molinari JA, Gleason MJ, Merchant VA. Sixteen years of experience with sterilization monitoring. Compendium 1994 Dec;15(12):1422-1424.

16. Hackney RW Jr, Crawford JJ, Tulis JJ. Using a biological indicator to detect potential sources of cross-contamination in the dental operatory. J Am Dent Assoc 1998 Nov;129(11):1567-1577.

17. Cuny E. The use of a process challenge device in dental office gravity displacement tabletop sterilizers. Am J Infect Control 2015 Oct;43(10):1131-1133.

18. McErlane B, Rosebush WJ, Waterfield JD. Assessment of the effectiveness of dental sterilizers using biological monitors. J Can Dent Assoc 1992 Jun;58(6):481-483.

19. Skaug N, Lingaas E, Nielsen O, Palenik CJ. Biological monitoring of sterilizers and sterilization failures in Norwegian dental offices in 1985 and 1996. Acta Odontol Scand 1999 Aug;57(4):175-180.

20. Andrés MT, Tejerina JM, Fierro JF. Reliability of biologic indicators in a mail-return sterilization-monitoring service: a review of 3 years. Quintessence Int 1995 Dec;26(12):865-870.

21. Werner HP, Kindt R, Borneff J. Testing the sterilisation effect of autoclaves by means of biological indicators (author's transl). Zentralbl Bakteriol Orig B 1975 Jul;160(4-5):458-472.
22. de Graaff J, Eijkman MA. Quality of the sterilization process in the dental practice. Ned Tijdschr Tandheelkd 1997 Sep;104(9):342-345.

23. Tavares Sdo S, de Sousa JT, Tipple AF, e Souza AC, Pimenta FC, Anders PS. Efficacy of the pasteur oven as sterilization equipment in dental offices. Rev Esc Enferm USP 2008 Mar;42(1): 160-167.

24. Podgórska M, Jakimiak B, Röhm-Rodowald E, Chojecka A. Assessment of disinfection and sterilization processes in dental practice as important factors in prevention of infections. Przegl Epidemiol 2009 Jan;63(4):545-550.

25. Röhm-Rodowald E, Jakimiak B, Chojecka A, ZmudaBaranowska M, Kanclerski K. Assessment of decontamination processes: cleaning, disinfection and sterilization in dental practice in Poland in the years 2011-2012. Przegl Epidemiol 2012 Jan;66(4):635-641.

26. Patiño-Marín N, Martínez-Castañón GA, Zavala-Alonso NV, Medina-Solís CE, Torres-Méndez F, Cepeda-Argüelles O. Biologic monitoring and causes of failure in cycles of sterilization in dental care offices in Mexico. Am J Infect Control 2015 Oct;43(10):1092-1095.

27. Corrêa EG, de Castilho AR, Pereira CV. Indicadores químicos e biológicos da eficácia de esterilização por autoclave ou estufa. Rev Odontol Ciênc 2009 Apr;24(2):156-160.

28. Prado ME, Santos SS. Avaliação das condições de esterilização de materiais odontológicos, em consultórios na cidade de Taubaté. Rev Bioc Taubaté 2002 Aug;8(1):61-70.

29. McCauley K. A review of the newly revised ISO 11138 series on the manufacture of biological indicators. SporeNews Biol Indic Newslett MesaLabs 2017;13(2):1-3.

30. Alfa MJ, Olson N, DeGagne P, Jackson M. Evaluation of rapid readout biological indicators for 132 degrees $C$ gravity and 132 degrees $C$ vacuum-assisted steam sterilization cycles using a new automated fluorescent reader. Infect Control Hosp Epidemiol 2002 Jul;23(7):388-392. 